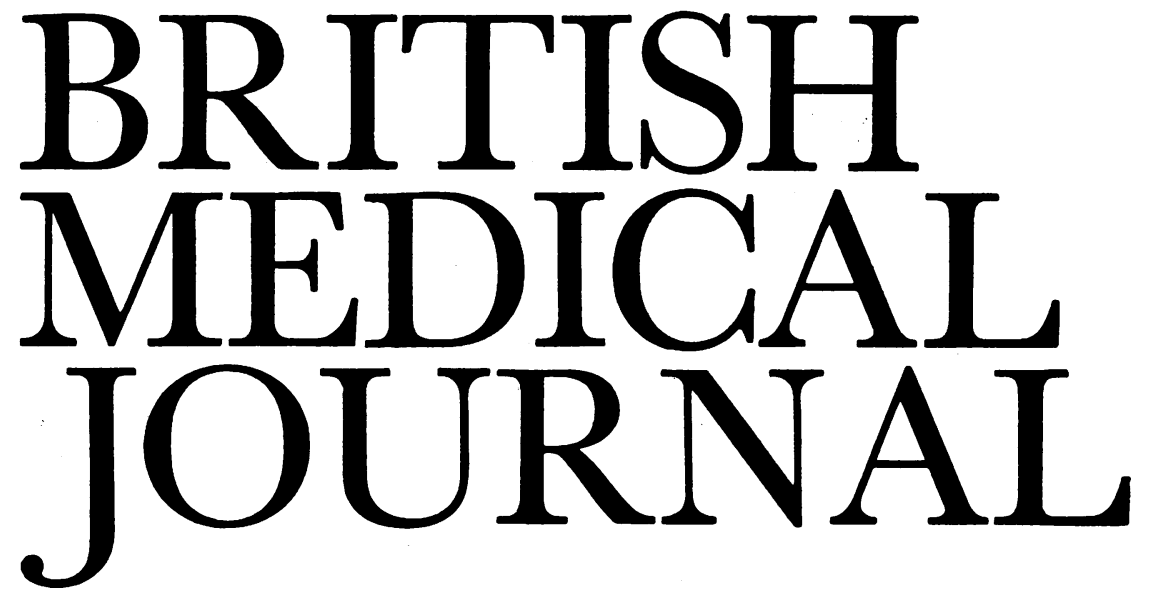

LONDON, SATURDAY 13 JUNE 1987

\title{
Extracranial-intracranial bypass, one; clinical trials, nil
}

A large prospective trial published last year seemed to show that extracranial-intracranial bypass was not effective for symptomatic but conventionally inoperable extracranial vascular disease. ${ }^{1}$ The trial, which was purportedly randomised but like all surgical trials was not blind, recruited 71 centres and 1377 randomised patients, and cost $\$ 9 \mathrm{~m}$. The null hypothesis was that the procedure would not make a difference to the incidence of cerebral events over the ensuing five years in patients already symptomatic from conventionally inoperable extracranial vascular disease. The outcome confirmed this negative view and at the time was widely regarded as having put the ultimate scientific boot into what seemed an elegant and rational procedure. ${ }^{2}$ Nobody doubts that the researchers made a valid deduction from the data received at the study centre, but whether this result can be generalised to the whole population is now open to doubt.

Dr T Sundt at the Mayo Clinic in a strenuous round of telephoning, writing, and interviewing contacted most of the international participants in the trial and has shown that the researchers randomised only a small proportion of the eligible patients who came under their care. ${ }^{3}$ The exact figures are open to dispute even after exhaustive inquiry and reanalysis ${ }^{4}$ because potential entrants who were medically ineligible were lumped together with those eligible but from whom consent for randomisation from either the referring doctor or the patient could not be obtained. Dr Sundt concluded from his survey of 57 of the centres that 1695 medically eligible patients were operated on outside the trial at a time when 1077 patients were randomised (560 to medical and 517 to surgical treatment). Extrapolating these figures to the whole trial may not be justified, but on their own they imply a high degree of selection. I find it difficult to penetrate the formal reanalysis undertaken by a committee of the American Association of Neurological Surgeons, ${ }^{4}$ but of all the patients in the study who were truly eligible 570 seem not to have been randomised at a time when 1377 were. Because of the method of collecting data the first figure may be too low; in addition, what actually happened to those excluded is not clear, although I expect that most had an operation. From all this incomplete and confused evidence we may conclude that $50-70 \%$ of eligible patients were not included in the trial.

To exclude this proportion is serious cause for concern and leads to an initial reaction that the trial was biased. Trial researchers have two approaches to try to overcome this source of bias. Firstly, randomisation may be undertaken before consent is sought, and the subgroup that is excluded by failure to obtain consent can then be analysed not only for its standard characteristics but also for the proportions that would have entered each treatment arm. Secondly, even if this is not done, excluded patients must have their treatment recorded and be followed up with the same rigorous standards that pertain to those who have been included. The study of extracranial-intracranial bypass failed to take any of these precautions, and therefore selection bias by doctors, patients, or both cannot be excluded. Bias must therefore be assumed.

Despite these shortcomings the outcome of the study may be correct for the whole population: there may, indeed, be no benefit from the surgical procedure over conventional medical management. Yet this conclusion cannot be supported from the trial, and the organisers are being uncompromising and rigid in continuing to claim on their evidence that the operation must be laid to rest. It is especially inappropriate for them to claim that only a small proportion of the global totals of treatable patients are used in controlled trials ${ }^{5}$; what is at issue is the failure to include all comers who present at a participating centre. Few would be convinced even if, as the editor of the New England Fournal of Medicine suggests, ${ }^{6}$ there was now to be a follow up of the excluded patients. Because the essence of a good trial is that it is prospective, who could avoid feeling that there will be subjective influences in a retrospective survey now that doubts have been raised? The practical and sad conclusion is that doctors looking after patients comparable with those designated eligible in the trial will either have to organise a new trial-possibly with a different end point - or still make up their minds about treatment on an ad hominem basis.

This episode emphasises the difficulties that exist at the interface between unbiased randomisation and informed consent. The statistician or detached clinical scientist rightly wants full randomisation. An effort of will by the patient's doctor can usually put him in the same frame of mind, although this may be damaging to the doctorpatient relationship. ${ }^{7}$ Recruitment to a trial may be prejudiced if this detachment cannot be achieved.$^{89}$ The patient 
has much greater difficulty than the doctor in achieving detachment: there is something unsettling to be told that doctors do not know the best treatment for your condition and that your treatment will be determined by tossing a coin. Moreover, when the two available treatments are quite different the patient can hardly be blamed, especially as a member of a technologically orientated community, if he chooses the procedure that appears more medically advanced.

The clinical trial is a powerful tool for uncovering therapeutic truth, and it can continue to be used provided that the subtlety of prior randomisation of the eligible sample and the reality of equality of follow up for those excluded are recognised. In addition, the numbers in the excluded group must not become so large as to deplete the test samples both quantitatively and qualitatively to numbers below which either valid statistical conclusions can be drawn or the results generalised back to the population. Should this happen, which may be the case most often when surgical and medical treatments are compared, then it will be back to the drawing board to seek other forms of validation that will satisfy our intellectual and emotional drive to get at the truth. ${ }^{10}$

Director,

H A F DUDLEY

Academic Surgical Unit,

St Mary's Hospital,

London W2 INY

1 EC/IC Bypass Study Group. Failure of extracranial-intracranial bypass to reduce the risk of ischemic stroke: results of an international randomized study. N Engl f Med 1985;313: $1191-200$

2 Plum F. Extracranial-intracranial bypass and cerebral vascular disease. $N$ Engl $f$ Med 1985;313:1221-23.

3 Sundt T. Was the international randomised trial of extracranial-intracranial arterial bypass representative of the population at risk? N Engl f Med 1987;316:814-6.

4 Committee of the American Association of Neurological Surgeons. The extracranial-intracranial bypass study. $N$ Engl f Med 1987;316:817-20.

5 Barnett HJM, Sackett D, Taylor DW, et al. Are the results of the extracranial-intracranial study trial-oneralisable? N Engl ₹ Med 1987;316:820-4.

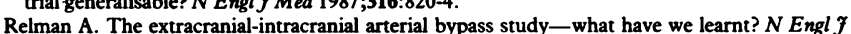
Med 1987;316:809-10.

7 Razis DV Clinical trials in cancer research-philosophical and methodological considerations: discussion paper. F $R$ Soc Med 1987;80:94-6.

8 Taylor KM, Margolese RG, Soskolne CL. Physicians' reasons for not entering eligible patients in a randomised clinical trial of surgery for breast cancer. $N$ Engl f Med 1984;310:385-6.

Dudley HAF. Informed consent in surgical trials. Br Med $\mathcal{F} 1984 ; 289: 937-8$.

10 Steiner G. Has truth a future? (Bronowski lecture). The Listener 1978;99:42-6.

\section{The future role of midwives}

Midwives have such a central role in the care of pregnant women that any proposals for changing their practice and training must have major implications for the maternity services. Such radical proposals are contained in a recent report from the Royal College of Midwives. ${ }^{1}$ Many midwives feel that their special training for looking after normal pregnant mothers is being frustrated by the current system, ${ }^{2-4}$ reducing them at times to mere chaperone-receptionists. ${ }^{5}$ Responding to this sentiment, the report is a discussion document which proposes a plan for midwife centred maternity care.

The objectives of these proposals are improved continuity of care, a more personalised service for pregnant mothers, and better job satisfaction for midwives. If implemented such new proposals would lead to substantial changes in the maternity services. Pregnant women would refer themselves initially to a midwife for the diagnosis of pregnancy and then be referred to a doctor. Normal pregnant women would have antenatal care, antenatal preparation, intrapartum care, delivery, and postpartum care from midwives alone. In addition, midwives would care for the newborn baby and offer family planning advice, with beds in the hospital delivery and postnatal areas and they would decide when to discharge mother and baby back to the community. Midwives would work in teams which would be based on either the hospital or the community. Each team would have a leader with an advanced diploma in midwifery, would have a stipulated case load, and would negotiate for its own finance and manpower. To meet all these demands midwife training would be extended to three years.

The objectives underlying the Royal College of Midwives' report are good and the proposals must be considered seriously. Nevertheless, several important questions have not been addressed-in particular, how would relationships between midwives and other professional groups develop? The present maternity care system is based on a partnership among general practitioners (with their detailed knowledge of the woman's history), obstetricians, anaesthetists, paediatricians, midwives, physiotherapists, and other members of the obstetric team. Once the puerperium is over the mothers and babies return to the community, where they are under the care of general practitioners and health visitors. Continuity of care cannot be defined within the terms of a single professional group and only midwives were on the report's working party. The major obstacle to continuity of care is the $37 \cdot 5$ hours working week for midwives, which means a minimum of five midwives to cover the 168 hours of one working week. Under the proposed system if the mother is to see a familiar face when she is in labour she will have to get to know five midwives-not a great improvement on the present situation-or midwives will have to adopt flexible working hours, and many of them have family responsibilities of their own. We need some indication of how continuity of care will be achieved in practice as well as what the legal implications for midwives undertaking total maternity care will be in an increasingly litigious society.

As a provisional discussion document the report by the Royal College of Midwives is valuable. Deficiencies in the present maternity service, especially continuity of care, are undeniable and we need new developments that will fully use the midwife's skills. The increasing use of midwife run antenatal clinics, ${ }^{6}$ of domino deliveries (domiciliary antenatal and postnatal care with the minimum of time spent in hospital), and of midwife supervised normal deliveries are welcome steps in the right direction. Obstetricians will, however, need to be reassured that there will be no return to the days of "fire brigade" obstetrics, when they were called to preventable emergencies in unfamiliar patients. The United Kingdom has developed a team approach to maternity care and it is crucial that the full role of the midwife is both recognised and developed within such a framework.

Peter W Howie

Professor of Obstetrics and Gynaecology,

Ninewells Hospital and Medical School, Dundee DD1 9SY

\footnotetext{
1 Royal College of Midwives. The role and education of the future midwife in the United Kingdom. London: Royal College of Midwives, 1987.

Walker JF. Midwife or obstetric nurse? Some perceptions of midwives and obstetricians of the role of the midwife. I Adv Nurs 1976;1:129-38.

3 Thomson AM. Planned or unplanned? Are midwives ready for the 1980s? Midwives Chronicle and Nursing Notes 1980;93:68-72.

Flirsing Notes 1980,93.68-72.

5 Robinson S. Norme mecol 1985;92:1-3.

6 Stuart B, Judge E. The return to the midwife? Midwives Chronicle and Nursing Notes 1984;97:8-9.
} 